\title{
Investigation of melt spinnability of plasticized polylactic acid biocomposites-containing intumescent flame retardant
}

\author{
Muhammad Maqsood $^{1}$ (D) Fabian Langensiepen ${ }^{1} \cdot$ Gunnar Seide $^{1}$
}

Received: 11 February 2019/Accepted: 22 May 2019/Published online: 29 May 2019

(c) The Author(s) 2019

\begin{abstract}
Biodegradable polymers from renewable resources have attracted interest due to environmental pollution caused by the disposal of non-degradable polymers, and engineering them to produce fibres of textile grade can improve the environmental sustainability of textile sector. Flame retardancy of polylactic acid (PLA) can be improved if used in intumescent system containing acidic and carbonic source; however, spinning them to produce fibres of textile grade is a big challenge. We therefore have prepared PLA composites containing phosphorous-nitrogen-based flame retardant as acidic source together with kraft lignin as carbonic source. Different quantities of flame retardant and kraft lignin were added to PLA matrix by melt blending and then hot-pressed to form moulding sheets. A modified polyester-based plasticizer was also incorporated to facilitate the spinnability of the composites. Limiting oxygen index values and UL-94 ratings of the composites were reported. The melt spinnability of composites was then assessed, and flame retardancy of knitted structures produced from multifilament yarns was tested by cone calorimetry. Composites containing up to $7 \%$ (m/m) of lignin were spinnable together with $10 \%(\mathrm{~m} / \mathrm{m})$ of plasticizer. A substantial decrease of $59 \%$ in heat release rate was observed compared to pure PLA. The mechanism of intumescence was also reported.
\end{abstract}

Keywords Melt spinning · Biopolymers · Plasticizer · Cone calorimetry $\cdot$ Flame retardancy

\section{Introduction}

Polylactide (PLA) is a thermoplastic synthetic biopolymer which is obtained from renewable resources such as corn, potato and cane biomass [1]. Due to its biodegradability and compostability, PLA can replace oil-based synthetic polymers in many applications in general and textile sector, in particular where disposal of non-degradable products is a big threat to environmental sustainability [2, 3]. The importance of PLA has grown over the last decade because it addresses current challenges, i.e. the depletion of

Muhammad Maqsood

muhammad.maqsood@maastrichtuniversity.nl

Fabian Langensiepen

fabian.langensiepen@maastrichtuniversity.nl

Gunnar Seide

gunnar.seide@maastrichtuniversity.nl

1 Aachen Maastricht Institute for Biobased Materials, Faculty of Science and Engineering, Maastricht University, Urmonderbaan 22, 6167 RD Geleen, The Netherlands petroleum reserves (the feedstock for conventional plastics) and the environmental harm caused by the irresponsible disposal of non-degradable polymers [4, 5]. Nowadays, PLA is more progressively used in fibres and fabrics applications $[6,7]$ because it can be spun by using techniques such as solution spinning, electrospinning and melt spinning [8, 9].

Initially, the applications of PLA were limited to fibrereinforced composites mainly in medical sector in the form of biodegradable sutures, vascular grafts and implants due to its biocompatibility $[10,11]$. Later on, PLA was more commonly used in the textile sector (clothing, home textiles and carpets) to replace the petroleum-based polyethylene terephthalate (PET) polymer because some of the physical and mechanical properties of PLA are comparable to that of PET $[12,13]$. However, flame retardancy of PLA is considered better to that of PET since the limiting oxygen index $(L O I)$ of neat PLA is $24-26 \%$ and that of neat PET is 18-20\% [14, 15]. Moreover, the smoke generation after ignition and self-extinguishing character of PLA is better to that of PET which makes this polymer even an 
interesting choice to be used in textile sector [16, 17]. Even so, PLA is still combustible and in order to be used in some technical textile applications the flame retardant properties of PLA need to be improved further [18].

In previous studies, various attempts have been made in order to improve the flame retardancy of PLA by using different formulations and additive types such as nitrogenbased compounds [19], phosphorous-based compounds [14], silicon-based compounds [20], expanded graphite- or carbon-based compounds [21], halogen-containing compounds [22] and halogen-free compounds as flame retardants [23, 24]. However, intumescent flame retardants (IFRs) containing an acidic and carbonic source have proven to be the most effective ones [5, 25]. The importance of IFRs containing biopolymers with biobased carbonic source and halogen-free acidic source has grown interest throughout the last decade in order to promote the sustainable approach towards flame retardancy of polymers [26]. Therefore, in continuation to this approach various researchers tried different formulations in IFR systems with different halogen-free acidic sources such as phytic acid [27], fumaric acid [28] and biobased carbonic sources such as cyclodextrin [29], lignin [30, 31], sorbitol [32], chitosan [28] and starch [33, 34].

Majority of the studies reported in the literature related to spinnability of flame-retardant composites $[10,21]$ have used predominantly petroleum-based carbonization agents or in the case of biobased carbonization agents either the trials were unsuccessful [28] or the loading content of the carbonic sources was not sufficient enough to achieve the desirable flame retardancy [35]. Therefore, the aim of the present study is to investigate the melt spinnability of PLAbased IFR composites comprising biobased (lignin) carbonic source and to engineer the polymer composition to spin multifilaments that can achieve acceptable range of flame retardancy in fabric form. A modified polyesterbased plasticizer was also incorporated into composites to facilitate the spinnability of composites. Composites were melt-spun to multifilament yarns on pilot-scale melt spinning machine and later on used to form knitted structures.

\section{Materials and methods}

\section{Materials}

Granular PLA Luminy ${ }^{\circledR}$ L130 ( $\geq 99 \%$ L-isomer) was attained from Total Corbion (Gorinchem, The Netherlands). A phosphorous-nitrogen-based non-halogenated flame retardant with commercial name (EXP PP/37), which is a fine-particle off-white powder containing ammonium polyphosphate with $19 \%(\mathrm{~m} / \mathrm{m})$ nitrogen and $20 \%(\mathrm{~m} / \mathrm{m})$ phosphorous (thermally stable up to $250{ }^{\circ} \mathrm{C}$ ), was obtained from Italmatch Chemicals (Genoa, Italy). The kraft lignin (KL) powder "UPM BioPiva 100" was purchased from UPM Biochemicals (Helsinki, Finland). A modified polyester-based plasticizing agent (PES) in white granular form (thermally stable up to $280{ }^{\circ} \mathrm{C}$ ) was obtained from Preluna (Ludwigshafen, Germany), to improve spinnability of composites. PLA, EXP, PES and KL were vacuum-dried at $100{ }^{\circ} \mathrm{C}$ for $4 \mathrm{~h}$ before compounding.

\section{Preparation of composites}

PLA/PES, PLA/EXP/PES and PLA/EXP/PES/KL composites were prepared using Coperion ZSK $\mathrm{Mc}^{18}$ twinscrew extruder (Stuttgart, Germany) at $190^{\circ} \mathrm{C}$. In the first phase, PLA/EXP/PES composites with EXP content of 5\%, $10 \%, 15 \%(\mathrm{~m} / \mathrm{m})$ and PES content of $10 \%(\mathrm{~m} / \mathrm{m})$ were compounded at screw rotation speed of $150 \mathrm{rpm}$. The temperatures of the three heating zones were kept at $180^{\circ} \mathrm{C}, 185^{\circ} \mathrm{C}$ and $190^{\circ} \mathrm{C}$, respectively. In the second phase, PLA/EXP/PES/KL composites with a KL content of $3,5,7$ and $10 \%(\mathrm{~m} / \mathrm{m})$ were compounded at screw rotation speed of $200 \mathrm{rpm}$. PLA/EXP/PES pellets were dosed in the first feeding zone, whereas KL was fed in the second feeding zone to ensure proper mixing. Sheets of the asprepared composites were produced by compression moulding at $190{ }^{\circ} \mathrm{C}$ for the subsequent testing along with sheets of pure PLA for comparison. The formulations with additives composition are presented in Table 1 .

\section{Yarn manufacturing}

Pure PLA, PLA/PES, PLA/EXP/PES and PLA/EXP/PES/ KL composites were melt-spun using Fourne Maschinenbau GmbH (Impekoven, Germany) pilot-scale melt spinning machine. Pellets were first fed into a hopper and then transported to a single-screw extruder where they were melted at a temperature range of $195-220{ }^{\circ} \mathrm{C}$. The melted material was then injected in a spinneret die of $1.2 \mathrm{~mm}$ diameter each, with the help of spinning pump rotating at constant revolutions per minute ensuring a homogeneous flow of the material. These single filaments coming out of the spinneret were then cooled at $18{ }^{\circ} \mathrm{C}$ by maintaining the cool air velocity of $0.5 \mathrm{~m} \mathrm{~s}^{-1}$ and then combined together to multifilaments by applying a spin finish. The multifilaments were collected on a take-up roller rotating at $250 \mathrm{~m} \mathrm{~min}^{-1}$ and then hot-drawn between two sets of rollers rotating at varying speeds. The speeds of the first and second set of heated rollers were maintained at $300 \mathrm{~m} \mathrm{~min}^{-1}$ and $350 \mathrm{~m} \mathrm{~min}^{-1}$, respectively, ensuring a draw ratio of 1.4 (maximum possible draw ratio). The multifilaments were then winded on the winder at $350 \mathrm{~m} \mathrm{~min}^{-1}$. A schematic diagram of pilot-scale melt spinning machine is shown in Fig. 1. 
Table 1 Additives composition in composites

\begin{tabular}{llcccc}
\hline No. & Formulations & PLA mass/\% & EXP mass/\% & PES mass/\% & KL mass/\% \\
\hline 1 & PLA & 100 & 0 & 0 & 0 \\
2 & PLA/PES10 & 90 & 0 & 10 & 0 \\
3 & PLA/EXP5/PES10 & 85 & 5 & 10 & 0 \\
4 & PLA/EXP10/PES10 & 80 & 10 & 10 & 0 \\
5 & PLA/EXP15/PES10 & 75 & 15 & 10 & 0 \\
6 & PLA/EXP15/PES10/KL3 & 72 & 15 & 10 & 3 \\
7 & PLA/EXP15/PES10/KL5 & 70 & 15 & 10 & 5 \\
8 & PLA/EXP15/PES10/KL7 & 68 & 15 & 10 & 7 \\
9 & PLA/EXP15/PES10/KL10 & 65 & 15 & 10 & 10 \\
\hline
\end{tabular}

Fig. 1 Schematic diagram of pilot-scale melt spinning machine and multifilament yarn produced

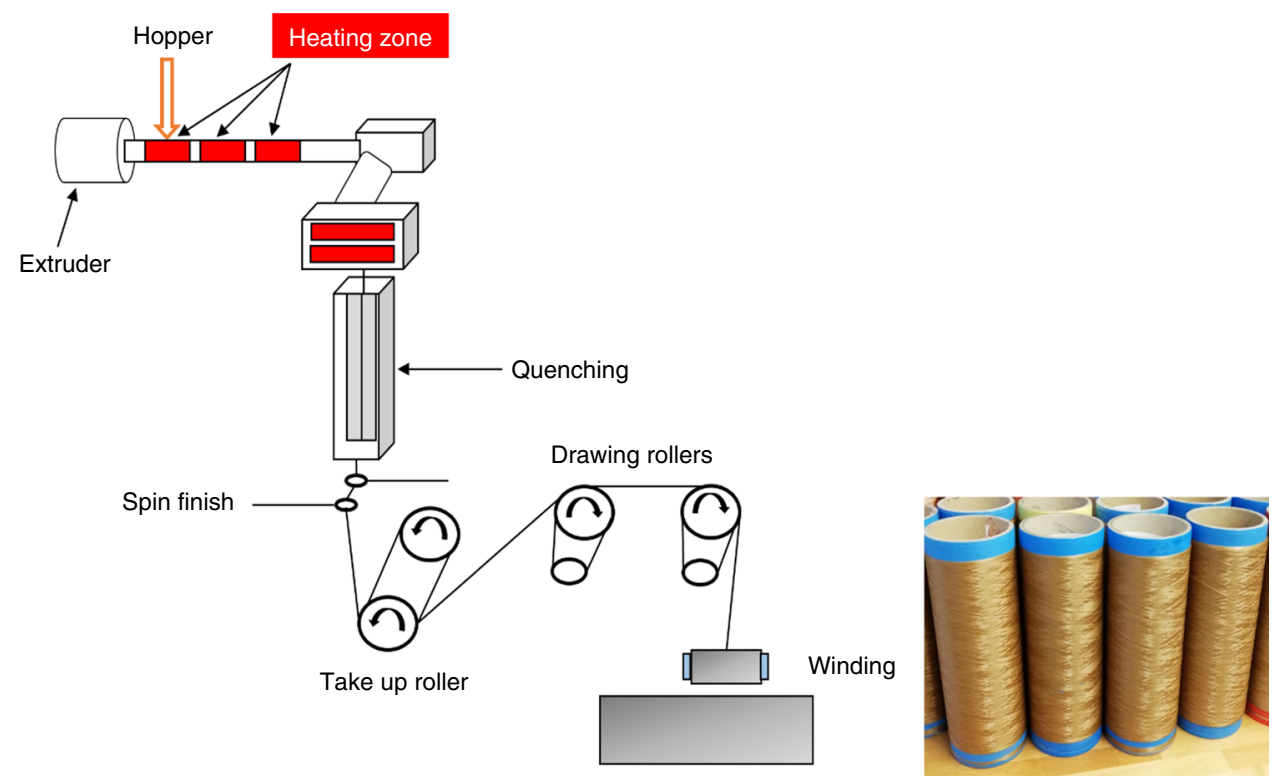

To further investigate the spinnability of as-prepared composites containing $\mathrm{KL}$, a design of experiment was prepared using half factorial design in MINITAB 18 statistical software. Four factors/variables with two levels each were considered in this study and are shown in Table 2. The design of experiment to investigate the spinnability of the composites is shown in Table 3.

Two different spinneret types containing 24 and 48 number of filaments, two maximum possible draw ratios of 1.2 and 1.4, two different drawing roller temperatures

Table 2 Factors and their levels

\begin{tabular}{llll}
\hline No. & Factors & Levels & \\
\hline 1 & No. of filaments & 24 & 48 \\
2 & Draw ratio & 1.2 & 1.4 \\
3 & Temperature of draw rollers $/{ }^{\circ} \mathrm{C}$ & 60 & 80 \\
4 & Yarn linear density $/$ dtex & 350 & 500 \\
\hline
\end{tabular}

$\left(60{ }^{\circ} \mathrm{C}\right.$ and $\left.80{ }^{\circ} \mathrm{C}\right)$ and two different yarn linear densities (350 and 500 dtex) of composites containing KL were investigated. It was observed that all 24 possible combinations were spinnable; however, their mechanical properties were almost in the same range since there was not much difference in the draw ratio of the filaments considering it as the main factor responsible for variation in the yarn mechanical properties. An average of their tenacity $\left(\mathrm{cN} \mathrm{tex}{ }^{-1}\right)$ and elongation at break $(\%)$ were recorded and discussed in Results and discussion section.

\section{Fabric manufacturing}

Multifilament yarns of linear density 500 dtex were knitted to form a fabric structure. Knitted fabrics were preferred over woven or nonwovens because of their easier processibility and drapeability. Single jersey structure was selected for fabric manufacturing in order to characterize their flammability by cone calorimetry. The areal densities of all the knitted fabrics were approximately $800 \mathrm{~g} \mathrm{~m}^{-2}$ with a fabric thickness of around about $3 \mathrm{~mm}$. 
Table 3 Design of experiment for spinning the composites containing KL

\begin{tabular}{|c|c|c|c|c|}
\hline Sample & No. of filaments & Draw ratio & Temperature of draw rollers $/{ }^{\circ} \mathrm{C}$ & Yarn linear density/dtex \\
\hline \multirow[t]{8}{*}{ PLA/EXP15/PES10/KL3 } & 24 & 1.2 & 60 & 350 \\
\hline & 48 & 1.2 & 60 & 500 \\
\hline & 24 & 1.4 & 60 & 500 \\
\hline & 48 & 1.4 & 60 & 350 \\
\hline & 24 & 1.2 & 80 & 500 \\
\hline & 48 & 1.2 & 80 & 350 \\
\hline & 24 & 1.4 & 80 & 350 \\
\hline & 48 & 1.4 & 80 & 500 \\
\hline \multirow[t]{8}{*}{ PLA/EXP15/PES10/KL5 } & 24 & 1.2 & 60 & 350 \\
\hline & 48 & 1.2 & 60 & 500 \\
\hline & 24 & 1.4 & 60 & 500 \\
\hline & 48 & 1.4 & 60 & 350 \\
\hline & 24 & 1.2 & 80 & 500 \\
\hline & 48 & 1.2 & 80 & 350 \\
\hline & 24 & 1.4 & 80 & 350 \\
\hline & 48 & 1.4 & 80 & 500 \\
\hline \multirow[t]{8}{*}{ PLA/EXP15/PES10/KL7 } & 24 & 1.2 & 60 & 350 \\
\hline & 48 & 1.2 & 60 & 500 \\
\hline & 24 & 1.4 & 60 & 500 \\
\hline & 48 & 1.4 & 60 & 350 \\
\hline & 24 & 1.2 & 80 & 500 \\
\hline & 48 & 1.2 & 80 & 350 \\
\hline & 24 & 1.4 & 80 & 350 \\
\hline & 48 & 1.4 & 80 & 500 \\
\hline
\end{tabular}

\section{Thermogravimetric analysis}

Thermogravimetric behaviour of composites was assessed using a TGA Q5000 device (TA Instruments, New Castle, Delaware, USA). The specimens (10-15 mg) were heated at a constant rate of $10{ }^{\circ} \mathrm{C} \min ^{-1}$ up to $700{ }^{\circ} \mathrm{C}$ under nitrogen at a flow rate of $50 \mathrm{~mL} \mathrm{~min}^{-1}$. The thermal decomposition temperature and the temperature at which maximum degradation took place were calculated along with the residual percentage of the sample compared to the initial mass. The thermogravimetric curves of specimens were plotted after analysis.

\section{Scanning electron microscopy}

The surface morphology and dispersion of additives in the PLA matrix were investigated by scanning electron microscopy (SEM) using a TM-1000 table-top microscope (Hitachi, Chiyoda, Tokyo, Japan). The samples were immersed in liquid nitrogen followed by freeze fracturing and gold sputtering to produce a conductive surface. In the case of multifilament yarns, morphology and additives deposition on yarns surface were also studied by SEM.

\section{Mechanical testing}

Mechanical properties such as tensile strength, elongation at break and Young's modulus of PLA composites were tested by Zwick Roell Z020TH Allround-line tabletop machine (Zwick GmbH \& Co.KG, Ulm, Germany) at a speed of $50 \mathrm{~mm} \mathrm{~min}{ }^{-1}$. The test specimens of dog bone shape were prepared as per standard EN ISO 527-2 method using moulding press. Specimens dimensions used were $170 \times 20 \times 3 \mathrm{~mm}^{3}$. The tenacity and elongation at break of multifilaments were also tested on Zwick Roell testing machine by using EN ISO 5079 standard method. The specimen lengths $(50 \mathrm{~mm})$ and rate of deformation $\left(50 \mathrm{~mm} \mathrm{~min}^{-1}\right)$ were kept constant for all samples. Ten specimens were prepared from each sample, and their average results with standard deviations were recorded. 


\section{Limiting oxygen index and UL-94 vertical burning test}

The limiting oxygen index $(L O I)$ is the fraction of oxygen that must be present to support burning; hence, higher $L O I$ values indicate lower flammability. The specimens $\left(100 \times 10 \times 3 \mathrm{~mm}^{3}\right.$, as required by ISO 4589$)$ were vertically placed in a glass column supplied with a mixture of oxygen and nitrogen gas, and were then ignited from above using a downward-pointing flame. The $L O I$ tests for pure PLA and PLA composites were conducted using a Stanton Redcroft instrument (Illinois Toolworks, Glenview, Illinois, USA).

The UL-94 test classifies materials based on their ability to either promote or inhibit the spread of fire once it has been ignited. UL-94 tests for pure PLA and PLA composites were conducted using specimens with dimensions of $100 \times 10 \times 3 \mathrm{~mm}^{3}$ as required by ISO 9773 . A flame was applied to the bottom of a vertically supported specimen, and the response was assessed after removing the flame. Specimens that self-extinguish and do not drip after burning are ranked highest in the classification $(\mathrm{V}-0)$.

\section{Cone calorimetry}

Cone calorimetry works on the principle of oxygen consumption and states that the total heat of combustion of a specimen depends on the quantity of oxygen consumed $[36,37]$. The cone calorimetry tests of knitted fabrics were conducted on specimens with dimensions of $100 \times 100 \times 3 \mathrm{~mm}^{3}$ as required by ISO 5660 using a Stanton Redcroft instrument. The samples were exposed to a heat flux of $35 \mathrm{~kW} \mathrm{~m}^{-2}$. We then recorded the heat release rate $(H R R)$, total heat release $(T H R)$, time to ignition (TTI) and percentage mass residue after burning of specimens. Three specimens from each sample were tested, and their average results were recorded.

\section{Results and discussion}

\section{Mechanism of intumescence}

EXP containing long-chain ammonium polyphosphate (Form II) was used as flame retardant in PLA polymer. Upon decomposition of ammonium polyphosphate, phosphoric acid and ammonia were formed. Phosphoric acid acted as acid catalyst in the dehydration process of carbonbased poly-alcohols in lignin. Upon reaction of acid catalyst (phosphoric acid) with hydroxyl groups in lignin, phosphate esters were formed which were decomposed later to release carbon dioxide and dehydration of lignin was taken place. In the gas phase, the emission of carbon dioxide helped in dilution of the oxygen present in air together with the by-products that were ignited during decomposition of the materials, whereas the resultant char layer in the condensed phase protected the underlying polymeric material from further burning by restricting the free passage of radiant heat and oxygen. This mechanism of intumescence is shown in Scheme 1.

\section{SEM analysis}

The dispersion of different proportions of EXP/PES and $\mathrm{EXP} / \mathrm{PES} / \mathrm{KL}$ in the PLA matrix was investigated by scanning electron microscopy to characterize the distribution of the additives, given that a uniform distribution achieves better fire retardant properties. Figure 2A shows SEM images of the composites, and Fig. 2B represents SEM images of multifilament yarns containing different $\%$ $(\mathrm{m} / \mathrm{m})$ of additives. We observed EXP, PES and KL particles of different sizes and shapes, with different levels of interfacial adhesion with the PLA matrix. In all formulations of PLA/EXP/PES and PLA/EXP/PES/KL, the additives were randomly distributed and non-uniform dispersion of the additives in PLA matrix was observed. However, we observed very weak interfacial bonding between the additives and PLA substrate as shown by the appearance of small holes during fracturing. In the case of multifilament yarns, the physical and mechanical properties are highly dependent on the loading content of the additives incorporated in the polymer matrix. As depicted by the SEM images of multifilament yarns in Fig. 2B, a nonuniform dispersion of additives was noticed and the addition of KL led to the development of irregularities in the yarn mainly due to higher loading content of viscous blends coupled with lower draw ratio (1.4) used during spinning process.

\section{LOI and UL-94 vertical burning tests for composites}

LOI and UL-94 tests were carried out to determine the flame retardant properties of the composites, and we also monitored their dripping behaviour when burning (Table 4).

Pure PLA did not pass the UL-94 vertical burning test because it was highly flammable with severe dripping. The LOI of pure PLA was $21.5 \%$ and that of PLA/PES10 was $20.3 \%$. The presence of $5 \%(\mathrm{~m} / \mathrm{m})$ EXP increased the $L O I$ of the composite (PLA/EXP5/PES10) to $24.6 \%$ and achieved a V-2 rating in the UL-94 test. The presence of $10 \%(\mathrm{~m} / \mathrm{m})$ EXP increased the LOI of the composite (PLA/ EXP10/PES10) to $26.4 \%$ and achieved a V-1 rating in the UL-94 test. When the proportion of EXP increased to $15 \%$ 
(a)

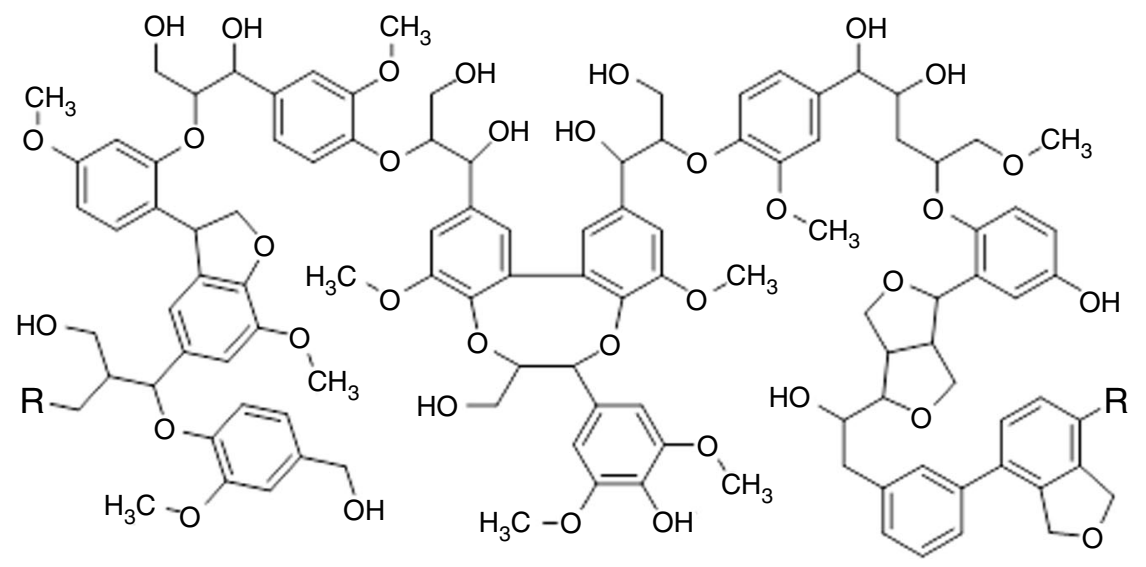

(b)

$$
\mathrm{H}\left[\begin{array}{c}
\mathrm{O} \\
\mathrm{O}-\mathrm{P}^{\prime \prime} \\
\vdots \\
\mathrm{O}^{-} \\
\mathrm{NH}_{4}^{+}
\end{array}\right]_{\mathrm{n}}
$$

ammonium polyphosphate

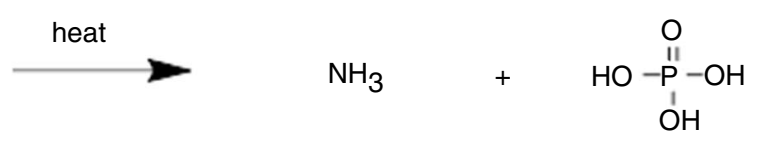

(c)<smiles>[R]CC(Cc1cc(CC2Cc3cc(CC(O)C(CO)Oc4ccc(C(O)C[2H])cc4OC)c(OC)cc3O2)cc(OC)c1CCO)OC</smiles>

(d)

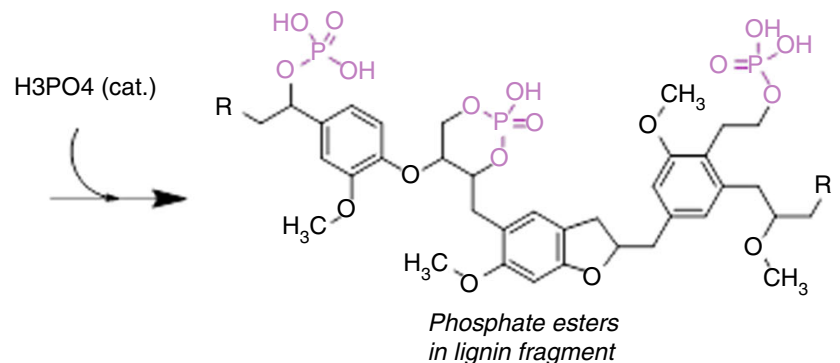<smiles>[2H]C=Cc1ccc(OC(=C)/C=C/c2cc3c(cc2OC)OC(Cc2cc(CC(C[2H])COC(=O)O)c(C=C)c(OC)c2)C3)c(OC)c1</smiles>

Scheme 1 Lignin structure (a), thermal decomposition of ammonium polyphosphate into ammonia and orthophosphoric acid (b), catalytic phosphorylation to produce phosphate esters (c), dehydration of lignin and formation of lignin-based char structure (d)

$(\mathrm{m} / \mathrm{m})$, the $L O I$ of the composite increased to $30.4 \%$ (PLA/ EXP15/PES10) and composite achieved a V-1 rating in the UL-94 test, although the composite did not show dripping behaviour during first flame application. However, all of the PLA/EXP/PES composites showed evidence of the dripping phenomenon when burning.

The addition of $3 \%(\mathrm{~m} / \mathrm{m}) \mathrm{KL}$ increased the $\mathrm{LOI}$ of the new composite (PLA/EXP15/PES10/KL3) from 30.4 to $32.8 \%$ and achieved $\mathrm{V}-0$ rating in the UL-94 test and also showed no evidence of dripping when burning. Similar results were observed with higher proportions of
KL. The LOI of the composites PLA/EXP15/PES10/KL5 and PLA/EXP15/PES10/KL7 was $34.1 \%$ and $36.7 \%$, respectively, and both achieved V-0 ratings in the UL-94 test with no evidence of dripping. The highest $L O I$ value of $38.1 \%$ was achieved with the composite containing $10 \%(\mathrm{~m} / \mathrm{m})$ of lignin (PLA/EXP15/PES10/KL10); however, this composite was not spinnable due to higher \% $(\mathrm{m} / \mathrm{m})$ of KL. These results confirmed that the introduction of KL as a natural carbonization agent increased the $L O I$ of the composites significantly and abolished the dripping phenomenon observed in composites lacking 
Fig. 2 SEM images of

A composites containing and

B multifilament yarns

containing PLA/EXP15/PES10

(a), PLA/EXP15/PES10/KL3

(b), PLA/EXP15/PES10/KL5

(c) and PLA/EXP15/PES10/

KL7 (d). Scale bar in all

panels $=180 \mu \mathrm{m}$,

magnification $=710 \times$
A
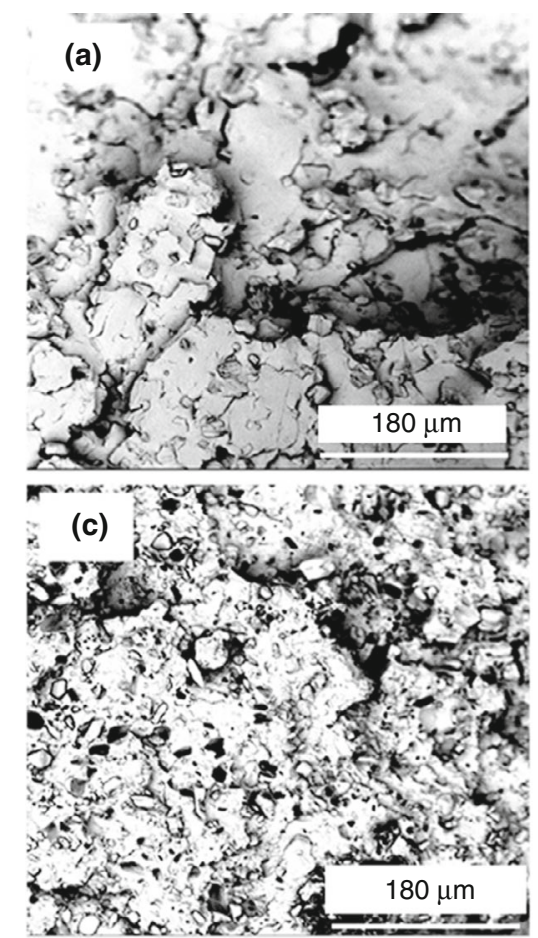

B
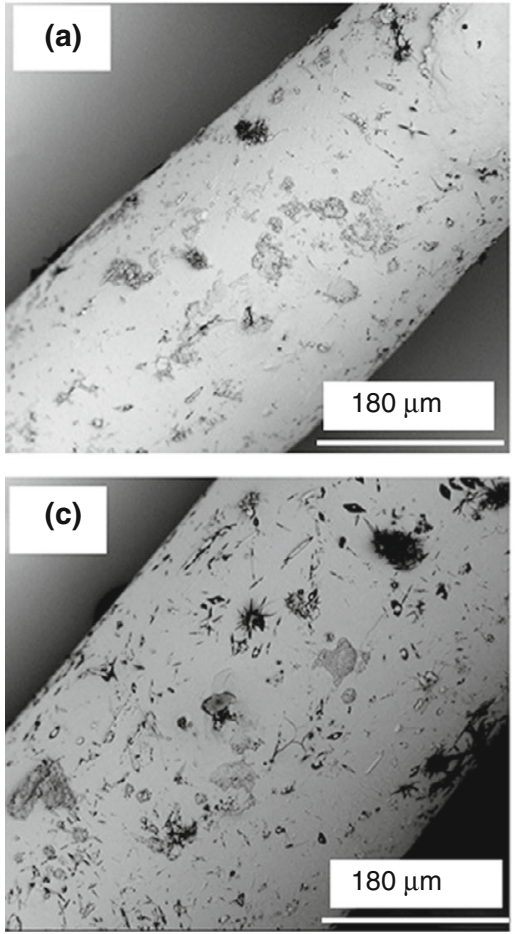
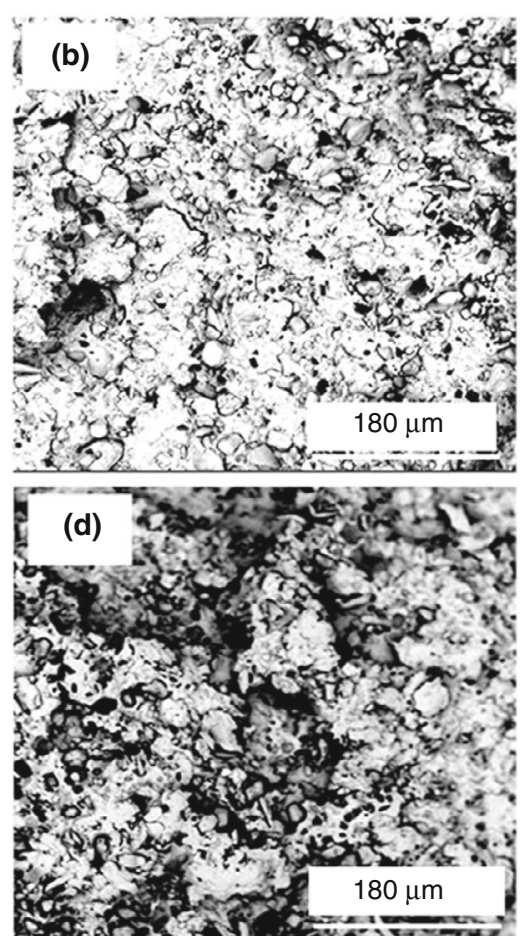

(b)
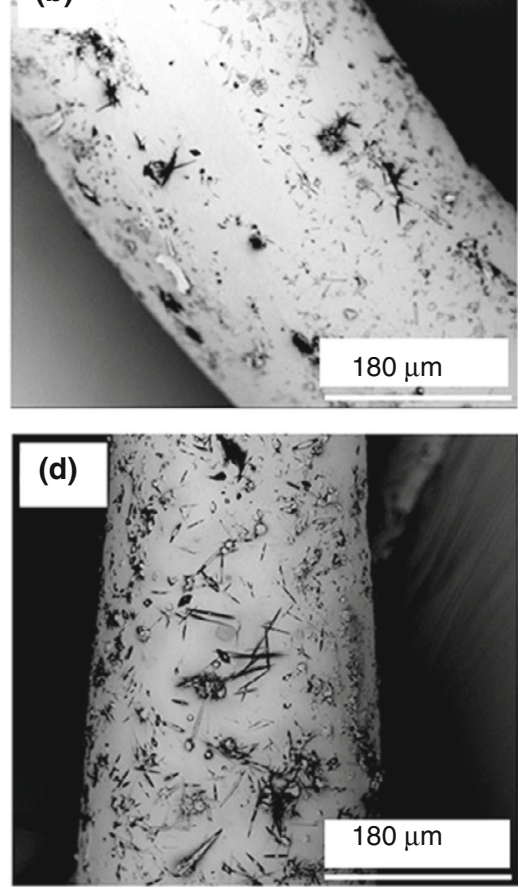

KL. All composites containing KL achieved a V-0 rating in the UL-94 vertical burning test. By increasing the amount of EXP and KL, a higher concentration of oxygen is needed to achieve the ignition of the sample due to the dilution of the fuel in the gas phase by the discharge of water vapour as a result of the dehydration of EXP and
KL. The addition of KL to the formulations not only increased the LOI of the samples but also increased the mass residue, providing enhanced shielding against heat transfer, and a barrier against the emission of pyrolysis gases which act as fuel. 
Table 4 Flame retardant properties of pure PLA and PLA composites

\begin{tabular}{lllll}
\hline No. & Formulations & LOI/\% & UL-94 & Dripping \\
\hline 1 & PLA & 21.5 & Failed & Y/Y \\
2 & PLA/PES10 & 20.3 & Failed & Y/Y \\
3 & PLA/EXP5/PES10 & 24.6 & V-2 & Y/Y \\
4 & PLA/EXP10/PES10 & 26.4 & V-1 & Y/Y \\
5 & PLA/EXP15/PES10 & 30.4 & V-1 & N/Y \\
6 & PLA/EXP15/PES10/KL3 & 32.8 & V-0 & N/N \\
7 & PLA/EXP15/PES10/KL5 & 34.1 & V-0 & N/N \\
8 & PLA/EXP15/PES10/KL7 & 36.7 & V-0 & N/N \\
9 & PLA/EXP15/PES10/KL10 & 38.1 & V-0 & N/N \\
\hline
\end{tabular}

PLA polylactic acid, EXP flame retardant, $K L$ kraft lignin, $P E S$ plasticizer, LOI limiting oxygen index, N/Y corresponds to NO/YES for dripping during the first/second flame application

The UL-94 vertical burning test determines a material's tendency to either extinguish or spread the flame once the specimen has been ignited. Pure PLA ignited during the first flame application (10 s), and the sample continued to burn until it was fully consumed as was the case with sample containing PLA/PES10. Although PLA/EXP5/ PES10 and PLA/EXP10/PES10 composites performed better as flame retardants (flame extinguished less than $30 \mathrm{~s}$ after each flame application; V-2 and V-1 ratings, respectively), the dripping of the burning sample ignited the cotton placed beneath. Similarly, PLA/EXP15/PES10 achieved a V-1 rating, although the flame was extinguished in less than $10 \mathrm{~s}$, but this sample still showed dripping behaviour during second flame application. In contrast, none of the composites containing KL were ignited even after the second application of flame and all achieved a V-0 rating without dripping due to the generation of char layer on the surface which isolated the remaining sample and prevented the propagation of the flame. In previous studies $[12,19]$, the addition of $30-40 \%(\mathrm{~m} / \mathrm{m})$ PER as a carbonization agent was sufficient to achieve only a V-2 rating, whereas here we found that as little as $3 \% \mathrm{KL}$ in the presence of $15 \%$ EXP and 10\% PES accomplished the target rating of $\mathrm{V}-0$.

\section{Thermogravimetric analysis}

The thermal decomposition and thermal stability of the composites were assessed by thermogravimetric analysis, and the residual mass of the samples was determined at $700{ }^{\circ} \mathrm{C}$. The thermal degradation and mass residue of the samples were compared to determine the influence of flame retardant (EXP) and carbonization agent (KL) on PLAbased composites. $T G$ curves and data for the samples heated in a nitrogen atmosphere are presented in Fig. 3 and Table 5, respectively.
In Table 5, the temperatures corresponding to 5\% and $50 \%$ mass loss for pure PLA and for each composite are represented by the $T_{5}$ and $T_{50}$ values, respectively, whereas the temperature corresponding to the maximum rate of mass losses is represented by $T_{\max }$. The degradation of pure PLA started at $318{ }^{\circ} \mathrm{C}$ and $50 \%$ loss occurred at $369^{\circ} \mathrm{C}$, with no residue left at $700{ }^{\circ} \mathrm{C}$ as almost the same case was observed with PLA/PES10 composite. A similar trend was observed for PLA/EXP5/PES10 composite for the $T_{5}$ and $T_{50}$ temperatures, but the residue left at $700{ }^{\circ} \mathrm{C}$ was $3.85 \%$ of the initial mass. For PLA/EXP10/PES10 and PLA/ EXP15/PES10, the initial decomposition temperatures and thermal stabilities were greater than the corresponding values for PLA/EXP5/PES10, with $5.93 \%$ and $8.42 \%$ residual mass left at $700{ }^{\circ} \mathrm{C}$. The introduction of lignin further improved the thermal stability of the composites. The initial decomposition temperatures and thermal stabilities of all composites containing lignin are higher compared to composites without lignin. For example, composite PLA/EXP15/PES10/KL3 increased the residual mass at $700{ }^{\circ} \mathrm{C}$ from 8.42 to $13.83 \%$ with higher initial decomposition temperature $\left(359{ }^{\circ} \mathrm{C}\right)$. The addition of 5 and $7 \%(\mathrm{~m} / \mathrm{m})$ of lignin (PLA/EXP15/PES10/KL5 and PLA/ EXP15/PES10/KL7) further improved the initial decomposition temperatures $\left(362{ }^{\circ} \mathrm{C}\right.$ and $369{ }^{\circ} \mathrm{C}$, respectively) with $15.54 \%$ and $17.31 \%$ residual mass left at $700{ }^{\circ} \mathrm{C}$. The highest thermal stability with maximum residual mass $\%$ $(20.12 \%)$ at $700{ }^{\circ} \mathrm{C}$ was observed in case of composite containing $10 \%(\mathrm{~m} / \mathrm{m})$ of lignin (PLA/EXP15/PES10/ KL10).

Figure 3 represents the $T G$ curves for PLA/EXP/PES and PLA/EXP/PES/KL composites in comparison with pure PLA. These composites differ in terms of their initial decomposition temperatures and thermal stabilities. PLA/ EXP15/PES10/KL10 containing $10 \%(\mathrm{~m} / \mathrm{m})$ of lignin was found to be more thermally stable and presented denser and more compact char layer with higher residual mass\% (20.12\%). All the composites containing lignin presented

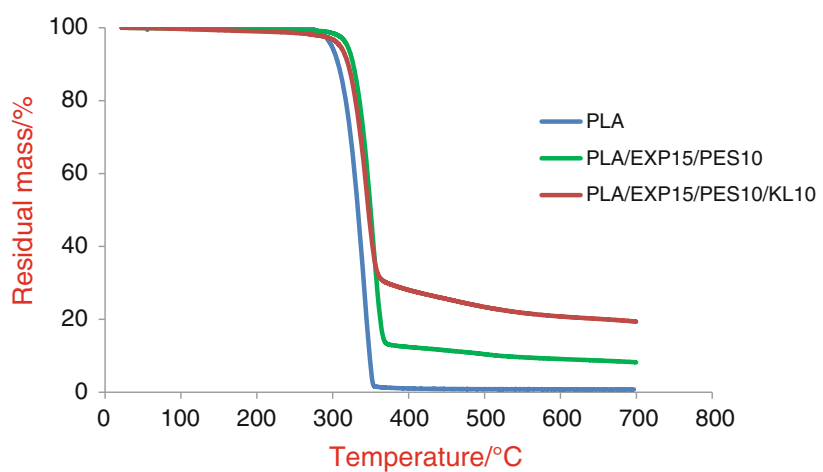

Fig. $3 T G$ curves of pure PLA, PLA/EXP/PES and PLA/EXP/PES/ KL composites 
Table 5 Data of thermogravimetric analysis

\begin{tabular}{llllll}
\hline No. & Formulations & $T_{5} /{ }^{\circ} \mathrm{C}$ & $T_{50} /{ }^{\circ} \mathrm{C}$ & $T_{\max } /{ }^{\circ} \mathrm{C}$ & Residual mass $/ \%$ \\
\hline 1 & PLA & 318 & 369 & 371 & 0.0 \\
2 & PLA/PES10 & 317 & 362 & 370 & 0.0 \\
3 & PLA/EXP5/PES10 & 320 & 370 & 375 & 3.8 \\
4 & PLA/EXP10/PES10 & 323 & 371 & 377 & 5.9 \\
5 & PLA/EXP15/PES10 & 342 & 372 & 376 & 8.4 \\
6 & PLA/EXP15/PES10/KL3 & 359 & 374 & 382 & 13.8 \\
7 & PLA/EXP15/PES10/KL5 & 362 & 376 & 383 & 15.5 \\
8 & PLA/EXP15/PES10/KL7 & 369 & 378 & 385 & 17.3 \\
9 & PLA/EXP15/PES10/KL10 & 376 & 381 & 390 & 20.1 \\
\hline
\end{tabular}

higher residual mass $\%$ at $700{ }^{\circ} \mathrm{C}$ due to charring ability of $\mathrm{KL}$ as a result of polycyclic aromatic hydrocarbons formation as indicated by Sharma et al. [38]; hence, composites containing lignin are superior in performance to composites without lignin. Thermogravimetric curves presented in Fig. 3 of pure PLA, PLA/EXP15/PES10 and PLA/EXP15/PES10/KL10 composites show the residual mass as a function of temperature, up to $700{ }^{\circ} \mathrm{C}$. The curves indicate that most of the thermal decomposition occurs between 300 and $400{ }^{\circ} \mathrm{C}$ and that pure PLA decomposes at a lower temperature than all the composites. Whereas all the composites degrade within a narrow temperature window, increasing the concentration of EXP causes more residual mass to remain at temperatures between 375 and $700{ }^{\circ} \mathrm{C}$, and adding $\mathrm{KL}$ at increasing concentrations has a further, additive effect. The thermal stabilities of the composites containing $\mathrm{KL}$ are therefore better than those of composites containing EXP alone. This behaviour is due to the combined effect of char forming ability of the polyhydric component (KL) and dehydration mechanism established by acid source (EXP) due to the formation of phosphate compounds which further enhances the dehydration of lignin resulting in higher char formation with compact structures.

\section{Mechanical properties of composites}

The mechanical properties of multi-component-based composites are dependent on the effective stress sharing between matrix and the additives incorporated. Therefore, in order to get acceptable mechanical strength of composites a uniform interfacial bonding between additives and matrix is needed. Moreover, the size of particles, \% $(\mathrm{m} / \mathrm{m})$ of additives incorporated as well as the adhesion between additives and matrix, influences the mechanical properties of polymer composites. As indicated in SEM images in the previous section, a weak interfacial bonding between additives and polymer matrix was observed due to which clustered and agglomerated particles were formed which affected the mechanical strength.
It can be seen in Table 6 that the tensile strength and elongation at break of pure PLA was $76.21(\mathrm{MPa})$ and $15.33 \%$, respectively. The addition of PES in PLA polymer (PLA/PES10) not only improved the ductility of the composite but elongation at break $(19.54 \%)$ also increased. However, with the addition of EXP $15 \%(\mathrm{~m} / \mathrm{m})$ in PLA matrix, the tensile strength and elongation at break started to decrease and reached $46.49(\mathrm{MPa})$ and $10.33 \%$, respectively. When $3 \%(\mathrm{~m} / \mathrm{m})$ of $\mathrm{KL}$ was incorporated together with $15 \%(\mathrm{~m} / \mathrm{m})$ of EXP in polymer matrix, tensile strength $(41.31 \mathrm{MPa})$ and elongation at break $(9.66 \%)$ were further reduced. The reduction in mechanical properties of PLA/EXP/PES and PLA/EXP/PES/KL composites is mainly due to weak interfacial bonding initiated by the difference in secondary valence forces among PLA matrix and additives incorporated [35, 39]. Another reason of weaker mechanical properties could be due to the degradation of PLA as well as of KL during preparation of PLA composites due to higher extrusion temperature which might have reduced the adsorbed chains mobility on the surface of the particles. Therefore, in order to improve the mechanical properties of PLA composites a uniform dispersion of additives in polymer matrix may be required which sometimes can be obtained by the use of a compatibilizer. The Young's modulus of pure PLA was $4742.43 \mathrm{MPa}$; it reduced gradually by the addition of EXP, and at $15 \%(\mathrm{~m} / \mathrm{m})$ loading of EXP it decreased to 3978.21 MPa. However, addition of KL in the composites led to further reduction in Young's modulus of the composites as it was $3237.54 \mathrm{MPa}$ at $10 \%(\mathrm{~m} / \mathrm{m})$ loading of KL.

\section{Mechanical properties of multifilament yarns}

To increase the loading content of flame retardant (EXP) and carbonization agent (KL) in PLA matrix, a plasticizer (PES) was incorporated as the third additive. The role of the plasticizer was to improve the spinnability of composites by reducing the rigidity of materials and to increase the elongation at break of multifilament yarns, although 
Table 6 Mechanical properties of pure PLA, PLA/PES, PLA/ EXP/PES and PLA/EXP/PES/ KL composites

\begin{tabular}{llll}
\hline Formulations & Tensile strength/MPa & Elongation at break/\% & Young's modulus/MPa \\
\hline PLA & $76.2 \pm 5$ & $15.3 \pm 0.4$ & $4742.4 \pm 14$ \\
PLA/PES10 & $65.3 \pm 7$ & $19.5 \pm 0.3$ & $4666.2 \pm 19$ \\
PLA/EXP5/PES10 & $52.9 \pm 6$ & $13.4 \pm 0.6$ & $4376.4 \pm 18$ \\
PLA/EXP10/PES10 & $49.8 \pm 7$ & $13.0 \pm 0.5$ & $4237.7 \pm 21$ \\
PLA/EXP15/PES10 & $46.4 \pm 8$ & $10.3 \pm 0.7$ & $3978.2 \pm 17$ \\
PLA/EXP15/PES10/KL3 & $41.3 \pm 9$ & $9.6 \pm 0.4$ & $3854.2 \pm 14$ \\
PLA/EXP15/PES10/KL5 & $40.4 \pm 6$ & $8.8 \pm 0.6$ & $3664.1 \pm 16$ \\
PLA/EXP15/PES10/KL7 & $38.9 \pm 7$ & $7.6 \pm 0.5$ & $3343.1 \pm 13$ \\
PLA/EXP15/PES10/KL10 & $37.2 \pm 5$ & $6.6 \pm 0.4$ & $3237.5 \pm 16$ \\
\hline
\end{tabular}

tenacity of multifilaments is mainly affected by its addition.

Composites containing PLA/EXP/PES and PLA/EXP/ $\mathrm{PES} / \mathrm{KL}$ were melt-spun, and it was observed that as the loading content of EXP and KL was increased, the multifilament yarns were not able to withstand the same draw ratio which was applied for pure PLA and only PLA/EXP5/ PES10 could be spun at the same processing conditions. For other compositions of composites, draw ratio was reduced gradually from 2 to 1.4 in order to spin the composites without breakage. This reduction in draw ratio resulted in lower mechanical properties of multifilament yarns produced from these composites predominantly due to amorphous nature with little or no crystallinity induced in the filament structure.

The tenacity and elongation at break of multifilament yarns are mainly influenced by the $\%(\mathrm{~m} / \mathrm{m})$ of the additives incorporated in the PLA matrix; therefore, the mechanical properties of the multifilament yarns containing higher amount of EXP and KL were on the lower side (Table 7) than that of multifilament yarns produced from pure PLA.

The lower mechanical properties of multifilament yarns containing KL and EXP are mainly due to non-uniform dispersion of the additives in PLA matrix due to which clustered and agglomerated particles were formed which produced cracks on the yarn's surface. At the SEM investigations, it turned out that the interfacial adhesion between the components was on a low level and large parts of additives with relative low aspect ratio were present. It is more likely that the large particles acted as starting point of failure during loading. Another reason could be as the lignin content was increased, hydroxyl groups present in lignin formed hydrogen bonds with PLA substrate, and as a result molecular chain gets more entangled which created free void spaces in the multifilament yarns by restricting molecular chain mobility; hence, their elongation at break reduced and they broke at much lower force compared to pure PLA as explained by Cayla et al. [35] and Wang et al. [25]. Due to this reason, it was not possible to spin composite containing $10 \%(\mathrm{~m} / \mathrm{m})$ of KL (PLA/EXP15/ PES10/KL10). Although mechanical properties of multifilament yarns seem to be on the lower side, they were sufficient enough to produce knitted structures.

\section{Cone calorimetry}

Cone calorimetry data for pure PLA and PLA composite fabrics are presented in Table 8 .

Five types of samples (pure PLA, PLA/EXP10/PES10, PLA/EXP15/PES10, PLA/EXP15/PES10/KL5 and PLA/ EXP15/PES10/KL7) were knitted in order to assess the influence of flame retardant's and lignin's content on their reaction to fire. The time to ignition (TTI) of fabrics produced from pure PLA and from PLA composites is presented in Table 8. TTI of a fabric knitted from pure PLA was $79 \mathrm{~s}$. However, with the addition of $15 \%(\mathrm{~m} / \mathrm{m})$ of EXP (PLA/EXP15/PES10), TTI of the fabric reduced to $55 \mathrm{~s}$ which was further decreased to $43 \mathrm{~s}$ when $15 \%(\mathrm{~m} / \mathrm{m})$ of EXP together with $7 \%(\mathrm{~m} / \mathrm{m})$ of lignin was incorporated in PLA. The decrease in ignition time of samples containing lignin can be attributed to the degradation of lignin during compounding and melt spinning since the degradation temperature of lignin is lower $\left(230^{\circ} \mathrm{C}\right)$ to that of $\operatorname{EXP}\left(270{ }^{\circ} \mathrm{C}\right)$ and PLA $\left(280^{\circ} \mathrm{C}\right)$. The decrease in ignition time for knitted fabrics containing lignin can also be attributed to the short fibres present on the surface of multifilament yarns due to partial degradation of filaments during spinning, which were easier to ignite, hence reducing the ignition time.

Heat release rate curves for pure PLA, PLA/EXP10/ PES10, PLA/EXP15/PES10, PLA/EXP15/PES10/KL5 and PLA/EXP15/PES10/KL7 knitted fabrics are presented in Fig. 4. Pure PLA fabric burnt much faster than the other samples and produced a steep curve with a high $P H R R$ (461 $\mathrm{kW} \mathrm{m}^{-2}$ ). In contrast, the PHRR of PLA/EXP10/ PES10 fabric was lower $\left(388 \mathrm{~kW} \mathrm{~m}^{-2}\right)$ and the further addition of $15 \%(\mathrm{~m} / \mathrm{m})$ EXP in PLA/EXP15/PES10 fabric reduced the $P H R R$ to $352 \mathrm{~kW} \mathrm{~m}{ }^{-2}$. The introduction of $5 \%$ $(\mathrm{m} / \mathrm{m})$ of $\mathrm{KL}$ in PLA/EXP15/PES10/KL5 fabric led to 
Table 7 Mechanical properties of pure PLA, PLA/PES, PLA/ EXP/PES and PLA/EXP/PES/ KL multifilament yarns

\begin{tabular}{lll}
\hline Formulations & Tenacity/cN tex & \\
\hline PLA & $19.8 \pm 3$ & Elongation at break/\% \\
PLA/PES10 & $17.9 \pm 4$ & $110.1 \pm 23$ \\
PLA/EXP5/PES10 & $12.4 \pm 1$ & $123.4 \pm 22$ \\
PLA/EXP10/PES10 & $10.9 \pm 2$ & $74.3 \pm 33$ \\
PLA/EXP15/PES10 & $9.5 \pm 2$ & $61.7 \pm 19$ \\
PLA/EXP15/PES10/KL3 & $7.3 \pm 2$ & $54.2 \pm 24$ \\
PLA/EXP15/PES10/KL5 & $7.1 \pm 1$ & $45.6 \pm 37$ \\
PLA/EXP15/PES10/KL7 & $6.7 \pm 1$ & $43.3 \pm 28$ \\
PLA/EXP15/PES10/KL10 & Not spun & $39.9 \pm 17$ \\
\hline
\end{tabular}

Table 8 Cone calorimetry data for pure PLA and PLA composites

\begin{tabular}{llllll}
\hline No. & Formulation & TTI/s & PHRR/kW m & THR/MJ m & Residual mass/\% \\
\hline 1 & PLA & 79 & 461 & 58.5 & 0 \\
2 & PLA/PES10 & 77 & 477 & 60.2 & 0 \\
3 & PLA/EXP5/PES10 & 66 & 415 & 55.7 & 9 \\
4 & PLA/EXP10/PES10 & 61 & 388 & 46.4 & 14 \\
5 & PLA/EXP15/PES10 & 55 & 352 & 44.6 & 17 \\
6 & PLA/EXP15/PES10/KL3 & 53 & 230 & 38.4 & 22 \\
7 & PLA/EXP15/PES10/KL5 & 48 & 205 & 26.1 & 25 \\
8 & PLA/EXP15/PES10/KL7 & 43 & 191 & 22.9 & 32 \\
\hline
\end{tabular}

TTI time to ignition, PHRR peak heat release rate, THR total heat release significant reduction of PHRR to $205 \mathrm{~kW} \mathrm{~m}^{-2}$. Remarkably, increasing the $\mathrm{KL}$ content to $7 \%(\mathrm{~m} / \mathrm{m})$ in PLA/ EXP15/PES10/KL7 fabric resulted in a substantial additional fall in the PHRR $\left(191 \mathrm{~kW} \mathrm{~m}^{-2}\right)$, which is $58.50 \%$ lower than the PHRR of pure PLA. These findings indicated that the combined effect of EXP and KL yielded a much thicker char layer on the surface of the knitted fabric after ignition, preventing further degradation of fabric and presenting higher residual mass $\%$ than the fabrics containing EXP alone.

Figure 5 shows the THR curves of pure PLA and the PLA/EXP/PES and PLA/EXP/PES/KL composites fabrics. The THR of pure PLA was $58.52 \mathrm{MJ} \mathrm{m}^{-2}$, whereas the

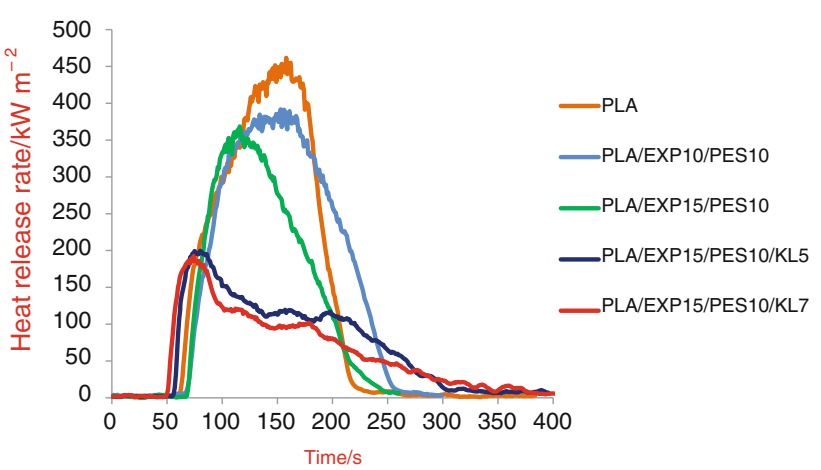

Fig. 4 Heat release rate of pure PLA, PLA/EXP/PES and PLA/EXP/ PES/KL fabrics values for PLA/EXP15/PES10 and PLA/EXP15/PES10/ KL7 knitted fabrics were 44.67 and $22.91 \mathrm{MJ} \mathrm{m}^{-2}$, respectively.

Figure 6 demonstrates SEM images of char residues after conducting cone calorimetry test. The char residues of PLA/EXP10/PES10 and PLA/EXP15/PES10 were loosely bound, and the structure in each case was porous and discontinuous due to insufficient char formation as shown by the SEM images of char residues. Heat and mass transfer therefore could not be inhibited effectively in these composites. In contrast, the samples containing KL, i.e. PLA/ EXP15/PES10/KL5 and PLA/EXP15/PES10/KL7, produced a more compact char with a dense and uniform

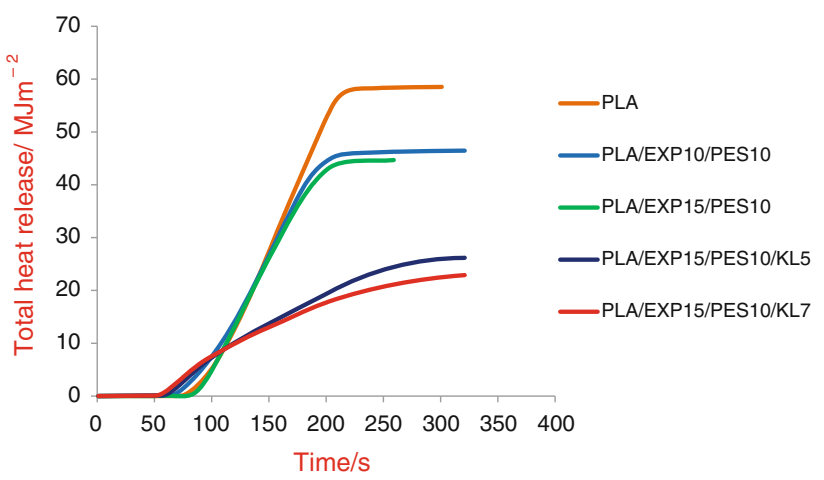

Fig. 5 Total heat release curves of pure PLA, PLA/EXP/PES and PLA/EXP/PES/KL fabrics 
Fig. 6 SEM analysis of char residues; PLA/EXP10/PES10 (a), PLA/EXP15/PES10 (b), PLA/EXP15/PES10/KL5 (c) and PLA/EXP15/PES10/ KL7 (d)
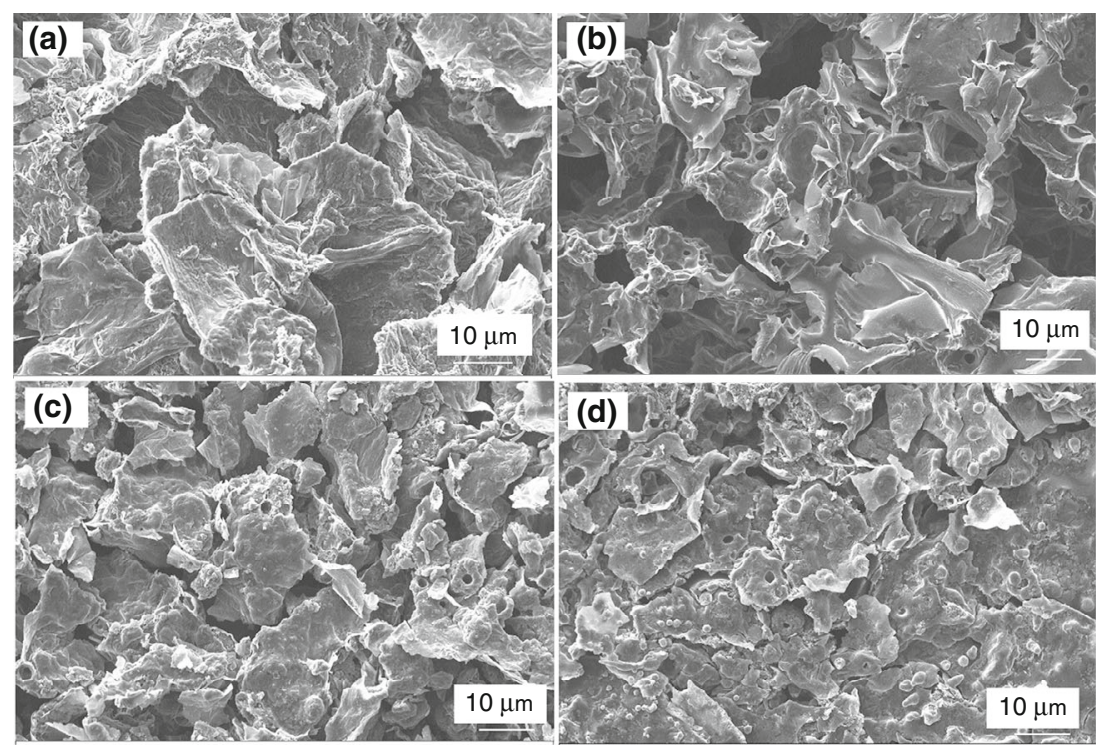

structure, reducing fuel and heat transfer to inhibit combustion and prevent further burning of the underlying polymeric substrate.

The weaker intumescence or a porous char structure in the samples containing EXP alone is caused by decreased viscosity in the condensed phase. The production of a uniform and compact char structure is mainly dependent on the viscosity of the sample in condensed phase. The lower viscosity in the condensed phase released the water vapours via bubbling which were produced by the dehydration of EXP and hence no longer available for the swelling of the char structure. If the viscosity in the condensed phase is too low, then EXP alone cannot generate enough pressure for the swelling of the substrate. Due to this porous char structure, both fuel gases (volatile compounds) and water vapours could easily pass through the unclosed cells; therefore, the HRR of the samples containing EXP alone is higher in comparison with $H R R$ of the samples containing EXP and KL. The reason is that the combined effect of acid source (EXP) and carbon source (KL) produced more compact char structure which hindered the discharge of fuel gases and water vapours which ultimately increased the viscosity of the condensed phase and as a result more swelling of the char was observed.

In samples containing EXP alone, residual mass\% was lower (Table 8) compared to samples containing KL. This is because the absence of KL lowered the viscosity of the char layer, in turn allowing vapour and gas bubbles to escape and reducing the degree of swelling because little pressure was allowed to build up as confirmed by SEM images of char residues in Fig. 6. The resulting porous structure allowed further fuel gases and water vapour to pass through the unclosed cells, increasing the PHRR. In contrast, the higher viscosity of the char layer containing KL made the char on fabric surface more compact and prevented the escape of gases and vapour, resulting in a pressure build up that increased the melt viscosity of the condensed phase and resulted in more swelling of the char. The combined effect of EXP and KL therefore reduced the PHRR to $191 \mathrm{~kW} \mathrm{~m}^{-2}$ which is $58.50 \%$ less than pure PLA.

This indicates that the combined effect of KL and EXP reduced the total quantity of fuel accessible for burning, which confirms the superior flame retardant performance of these fabrics. The high concentrations of EXP and KL diluted the substrate, providing less material for continued burning. Thermal decomposition therefore led to the dehydration of EXP, and the resulting water vapours cooled the gas phase and diluted the fuel, thus reducing the total heat release $(T H R)$ in proportion with the increasing EXP and KL content. The presence of KL exacerbated this effect because the emission of pyrolysis gases was inhibited by the formation of the char layer, which not only provided a physical barrier but also enhanced the heat shielding effect.

\section{Conclusions}

In this study, melt spinnability, thermal stability, mechanical properties and fire-related properties of PLA composites prepared by melt blending on twin-screw extruder comprising phosphorous-nitrogen-based flame retardant (EXP), kraft lignin (KL) and plasticizer (PES) were investigated. Composites containing up to $3 \%(\mathrm{~m} / \mathrm{m})$ of $\mathrm{KL}$ were comparatively easier to spin than composites 
containing $5 \%$ or $7 \%(\mathrm{~m} / \mathrm{m})$ of $\mathrm{KL}$ due to lesser molecular chain mobility with higher loading content of KL; however, composites containing up to $7 \%(\mathrm{~m} / \mathrm{m})$ of KL together with $15 \%(\mathrm{~m} / \mathrm{m})$ of EXP and $10 \%(\mathrm{~m} / \mathrm{m})$ of PES (plasticizer) were spinnable, but breakage of individual filaments were seen during melt spinning. With higher loading content of KL and EXP, elongation at break of multifilaments was decreased and multifilaments with lower mechanical properties were obtained. Thermal stabilities of PLA composites containing $\mathrm{KL}$ were improved with higher residual mass $\%(20.12 \%)$ at $700{ }^{\circ} \mathrm{C}$ due to greater charring ability of the compound. Flame retardant properties of knitted fabrics produced from these composites were investigated by cone calorimetry. The $H R R$ and $T H R$ of the knitted fabrics containing KL were significantly lower than the corresponding values for pure PLA and composites containing EXP alone. A remarkably low HRR was observed for PLA/EXP15/PES10/KL7 knitted fabric $\left(191 \mathrm{~kW} \mathrm{~m}^{-2}\right)$ which is $58.50 \%$ less than the $H R R$ of pure PLA. Higher loading content of KL could not delay the ignition time as TTI of knitted fabrics containing $\mathrm{KL}$ was lower than that without KL, but a substantial decline in $H R R$ and $T H R$ was observed.

Acknowledgements This research work was funded by Operational Programme South Netherlands (OP ZUID) [Grant Number $35930032 \mathrm{~N}$ ] under the project BioTex Fieldlab. Authors would also like to acknowledge "Chemelot Innovation and Learning Labs" (CHILL) located at Brightlands Chemelot Campus for their technical support in the project.

\section{Compliance with ethical standards}

Conflict of interest The authors declare that they have no conflict of interest.

Open Access This article is distributed under the terms of the Creative Commons Attribution 4.0 International License (http://creative commons.org/licenses/by/4.0/), which permits unrestricted use, distribution, and reproduction in any medium, provided you give appropriate credit to the original author(s) and the source, provide a link to the Creative Commons license, and indicate if changes were made.

\section{References}

1. Fox DM, Lee J, Citro CJ, Novy M. Flame retarded poly(lactic acid) using POSS-modified cellulose. 1. Thermal and combustion properties of intumescing composites. Polym Degrad Stab. 2013;98:590-6. https://doi.org/10.1016/j.polymdegradstab.2012. 11.016.

2. Fukushima K, Murariu M, Camino G, Dubois P. Effect of expanded graphite/layered-silicate clay on thermal, mechanical and fire retardant properties of poly(lactic acid). Polym Degrad Stab. 2010;95:1063-76. https://doi.org/10.1016/j.polymdegrad stab.2010.02.029.

3. Gui H, Xu P, Hu Y, Wang J, Yang X, Bahader A, et al. Synergistic effect of graphene and an ionic liquid containing phosphonium on the thermal stability and flame retardancy of polylactide. RSC Adv R Soc Chem. 2015;5:27814-22. https:// doi.org/10.1039/C4RA16393A.

4. Karim MN, Rigout M, Yeates SG, Carr C. Surface chemical analysis of the effect of curing conditions on the properties of thermally-cured pigment printed poly (lactic acid) fabrics. Dye Pigment. 2014;103:168-74. https://doi.org/10.1016/j.dyepig. 2013.12.010.

5. Lin HJ, Liu SR, Han LJ, Wang XM, Bian YJ, Dong LS. Effect of a phosphorus-containing oligomer on flame-retardant, rheological and mechanical properties of poly (lactic acid). Polym Degrad Stab. 2013;98:1389-96. https://doi.org/10.1016/j.polymdegrad stab.2013.03.025.

6. Lin H, Han L, Dong L. Thermal degradation behavior and gas phase flame-retardant mechanism of polylactide/PCPP blends. J Appl Polym Sci. 2014;131:1-11.

7. Murariu M, Bonnaud L, Yoann P, Fontaine G, Bourbigot S, Dubois P. New trends in polylactide (PLA)-based materials: "Green" PLA-Calcium sulfate (nano)composites tailored with flame retardant properties. Polym Degrad Stab. 2010;95:374-81.

8. Murariu M, Dechief AL, Paint Y, Peeterbroeck S, Bonnaud L, Dubois P. Polylactide (PLA)-Halloysite nanocomposites: Production. Morphology and key-properties. J Polym Environ. 2012;20:932-43.

9. Reti C, Casetta M, Duquesne S, Bourbigot S, Delobel R. Flammability properties of intumescent PLA including starch and lignin. Polym Adv Technol. 2006;17:395-418.

10. Solarski S, Mahjoubi F, Ferreira M, Devaux E, Bachelet P, Bourbigot S, et al. (Plasticized) Polylactide/clay nanocomposite textile: thermal, mechanical, shrinkage and fire properties. J Mater Sci. 2007;42:5105-17.

11. Suardana N, Kyoo M. Effects of diammonium phosphate on the flammability and mechanical properties of bio-composites. Mater Des. 2011;32:1990-9. https://doi.org/10.1016/j.matdes.2010.11. 069.

12. Teoh EL, Mariatti M, Chow WS. Thermal and flame resistant properties of poly (lactic acid)/poly (methyl methacrylate) blends containing halogen-free flame retardant. Procedia Chem; 2016;19:795-802. http://www.sciencedirect.com/science/article/ pii/S1876619616001339.

13. Wang DY, Leuteritz A, Wang YZ, Wagenknecht U, Heinrich G. Preparation and burning behaviors of flame retarding biodegradable poly(lactic acid) nanocomposite based on zinc aluminum layered double hydroxide. Polym Degrad Stab. 2010;95:2474-80. https://doi.org/10.1016/j.polymdegradstab.2010. 08.007.

14. Wang DY, Song YP, Lin L, Wang XL, Wang YZ. A novel phosphorus-containing poly(lactic acid) toward its flame retardation. Polymer (Guildf). 2011;52:233-8. https://doi.org/10. 1016/j.polymer.2010.11.023.

15. Wang K, Wang J, Zhao D, Zhai W. Preparation of microcellular poly(lactic acid) composites foams with improved flame retardancy. J Cell Plast. 2017;53:45-63.

16. Wei LL, Wang DY, Chen HB, Chen L, Wang XL, Wang YZ. Effect of a phosphorus-containing flame retardant on the thermal properties and ease of ignition of poly(lactic acid). Polym Degrad Stab. 2011;96:1557-61. https://doi.org/10.1016/j.poly mdegradstab.2011.05.018.

17. Zhan J, Song L, Nie S, Hu Y. Combustion properties and thermal degradation behavior of polylactide with an effective intumescent flame retardant. Polym Degrad Stab. 2009;94:291-6. https://doi. org/10.1016/j.polymdegradstab.2008.12.015.

18. Bourbigot S, Fontaine G. Flame retardancy of polylactide: an overview. Polym Chem. 2010;1:1413-22.

19. Bourbigot S, Duquesne S, Fontaine G, Bellayer S, Turf T, Samyn F. Characterization and reaction to fire of polymer 
nanocomposites with and without conventional flame retardants. Mol Cryst Liq Cryst. 2008;486:37-41.

20. Qian Y, Wei P, Jiang P, Li Z, Yan Y, Ji K. Aluminated mesoporous silica as novel high-effective flame retardant in polylactide. Compos Sci Technol. 2013;82:1-7. https://doi.org/10.1016/ j.compscitech.2013.03.019.

21. Solarski S, Mahjoubi F, Ferreira M, Devaux E, Bachelet P, Bourbigot $\mathrm{S}$, et al. Designing Polylactide/Clay nanocomposites for textile applications: effect of processing conditions, spinning, and characterization. Polym Polym Compos. 2013;21:449-56.

22. Thunga M, Chen K, Grewell D, Kessler MR. Bio-renewable precursor fibers from lignin/polylactide blends for conversion to carbon fibers. Carbon N Y. 2014;68:159-66. https://doi.org/10. 1016/j.carbon.2013.10.075.

23. Di Blasi C, Branca C, Galgano A. Effects of diammonium phosphate on the yields and composition of products from wood pyrolysis. Ind Eng Chem Res. 2007;46:430-8.

24. Katsoulis C, Kandare E, Kandola BK. The combined effect of epoxy nanocomposites and phosphorus flame retardant additives on thermal and fire reaction properties of fiber-reinforced composites. J Fire Sci. 2011;29:361-83.

25. Wang J, Manley RSJ, Feldman D. Synthetic polymer-lignin copolymers and blends. Prog Polym Sci. 1992;17:611-46.

26. Idumah CI, Hassan A. Emerging trends in flame retardancy of biofibers, biopolymers, biocomposites, and bionanocomposites. Rev Chem Eng. 2016;32:115-48.

27. Cheng XW, Guan JP, Tang RC, Liu KQ. Phytic acid as a biobased phosphorus flame retardant for poly(lactic acid) nonwoven fabric. J Clean Prod. 2016;124:114-9. https://doi.org/10.1016/j. jclepro.2016.02.113.

28. Zhang T, Yan H, Shen L, Fang Z, Zhang X, Wang J, et al. Chitosan/phytic acid polyelectrolyte complex: a green and renewable intumescent flame retardant system for ethylene-vinyl acetate copolymer. Ind Eng Chem Res. 2014;53:19199-207.

29. Feng JX, Su SP, Zhu J. An intumescent flame retardant system using $\beta$-cyclodextrin as a carbon source in polylactic acid (PLA). Polym Adv Technol. 2011;22:1115-22.

30. Zhang R, Xiao X, Tai Q, Huang H, Hu Y. Modification of lignin and its applications as a char agent in intumescent flame retardant polylactic acid. Polym Eng Sci. 2012. https://doi.org/10.1002/ pen.20921.

31. Zhang R, Xiao X, Tai Q, Huang H, Yang J, Hu Y. Preparation of lignin-silica hybrids and its application in intumescent flameretardant poly(lactic acid) system. High Perform Polym. 2012;24:738-46. https://doi.org/10.1177/0954008312451476.

32. Laufer G, Kirkland C, Cain AA, Grunlan JC. Clay-chitosan nanobrick walls: completely renewable gas barrier and flameretardant nanocoatings. ACS Appl Mater Interfaces. 2012;4:1643-9.

33. Wang J, Ren Q, Zheng W, Zhai W. Improved flame-retardant properties of poly(lactic acid) foams using starch as a natural charring agent. Ind Eng Chem Res. 2014;53:1422-30.

34. Maqsood M, Seide G. Investigation of the flammability and thermal stability of halogen-free intumescent system in biopolymer composites containing biobased carbonization agent and mechanism of their char formation. Polymers (Basel). 2018;11:1-16.

35. Cayla A, Rault F, Giraud S, Salaün F, Fierro V, Celzard A. PLA with intumescent system containing lignin and ammonium polyphosphate for flame retardant textile. Polymers (Basel). 2016;8:331.

36. Afriyie R, Qiang M, Solomon X, Jin AC. Correlation analysis of cone calorimetry and microscale combustion calorimetry experiments. J Therm Anal Calorim. 2019;136:589-99. https://doi.org/ 10.1007/s10973-018-7661-5.

37. An W, Jiang L, Sun J, Liew KM. Correlation analysis of sample thickness, heat flux, and cone calorimetry test data of polystyrene foam. J Therm Anal Calorim. 2015;119:229-38.

38. Sharma RK, Wooten JB, Baliga VL, Lin X, Chan WG, Hajaligol MR. Characterization of chars from pyrolysis of lignin. Fuel. 2004;83:1469-82.

39. Arrieta MP, López J, López D, Kenny JM, Peponi L. plasticized PLA-PHB blends reinforced with cellulose nanocrystals. Ind Crop Prod. 2015. https://doi.org/10.1016/j.indcrop.2015.12.058.

Publisher's Note Springer Nature remains neutral with regard to jurisdictional claims in published maps and institutional affiliations. 